\title{
EMPATHY AND BURNOUT AMONG PHYSICIANS PROVIDING REANIMATOLOGICAL AND SURGICAL TREATMENT
}

\author{
Dalia Antiniené, Žydrūnė Kaklauskaitė \\ Lithuanian University of Health Sciences, Kaunas, Lithuania
}

\begin{abstract}
Background. Among scientific publications it is observed that in medicine the aspect of interpersonal connection is underestimated while providing medical help (Steinhausen et al., 2014), and not enough attention is being allocated to the effect of a physician's empathy in the treatment process (Hojat et al., 2002a). The lack of scientific publications shows that this topic is under-researched and relevant. Thus, the purpose of the study was to determine relationships between empathy and burnout among practicing physicians.

Methods. A total of 185 practicing physicians who provide reanimatological and surgical treatment participated in the research. A questionnaire was designed for the study, consisting of the Jefferson Scale of Physician Empathy (Hojat, 2016), Copenhagen Burnout Inventory (Kristensen Borritz, Villadsen, \& Christensen, 2005).

Results. Research revealed that the expressiveness of empathy between doctors is not related to sex, age, work experience and speciality $(p>.05)$. Also, it was found that younger physicians experienced more work-related burnout $(p=.04)$. the study showed that there was no statistically significant relationship between empathy and burnout among physicians $(p>.05)$.

Conclusions. Research showed that physician's empathy was not related to demographic factors. Findings revealed that younger doctors experienced more work-related burnout than the older ones. Finally, connection between empathy and burnout was not found.
\end{abstract}

Keywords: empathy, personal burnout, work-related burnout, patient-related burnout, physician.

\section{INTRODUCTION}

$\mathrm{T}$ The term of empathy was first used in 1759. Adam Smith was the first to use the said term describing it as sympathy when another person is in plight or joy when somebody experiences success. In general, Smith conceptualized that empathy is an emotion, which is characteristic of all people and arises when one person sees another in emotional situations (Davis, 1994). Empathy is divided into cognitive and emotional components. Cognitive component involves accurate perception of the situation of another person, whereas emotional component is the existence of the person's connection with others and emotional reaction to experiences of other people (Davis, 1983, quoted in Regher,
Goldberg, \& Hughes, 2002). In medicine, empathy is distinguished as one of the most significant factors in patient's care, which promotes prosocial behaviour and helps to create high quality health care services (Ahrweiler, Neumann, Goldblatt, Hahn, \& Scheffer, 2014).

In the scientific literature, it is observed that in medicine the aspect of interhuman connection in delivering medical treatment is still underestimated (Steinhausen et al., 2014) and insufficient attention is being paid to empathy of physicians and empathy associations with other psychological or professional factors. The lack of such studies prevents medical schools from helping their students to achieve the most optimal level of empathy, which is necessary for practical work. (Hojat et al., 2002b). 
Meanwhile professional burnout was first mentioned in the scientific literature by Freudenberger (1974) who defined it as tiredness, mistakes, energy and strength loss or as the state of running out of inner resources because of unsatisfied wishes and needs (Ozkula \& Durukan, 2017). The said state develops because of long term interpersonal stressors at work (Maslach \& Leiter, 2016). Work-related burnout syndrome consists of three components, such as exhaustion, depersonalization or cynicism and low sense of achievement (Lathrop, 2017).

In the scientific literature, it is indicated that one fifth of physicians suffer from clinical burnout or are at risk of experiencing it (Van der Ploeg et al., 2003). It has been determined that physicians who are at lower risk of professional burnout are more optimistic, communicate more with patients and are more inclined to help them, which contributes to improved patient health care (Scheepers, Boerebach, Arah, Heineman, \& Lombarts, 2015).

Studies show that so far it is not clear how job related factors, such as big work load, which causes work-related burnout, working environment, the chosen specialization, encounter with critical events, etc. impact empathy of a physician (Pedersen, 2009). It is also being observed that medical professionals feel insufficient attention to their psychological health (Venyte, 2008), more than half of medical personnel constantly experience emotional stress at work (Zdanavičienè, 2013). We were not able to find studies about empathy and professional burnout among Lithuanian physicians; therefore it may be assumed that a study determining correlation between empathy and professional burnout would be useful pursuing the improvement of psychological health of physicians, looking for better patient-doctor connection and thus better quality of medical treatment.

The object of the present study was correlation between empathy and professional burnout.

The aim of the study was to determine peculiarities of correlation between empathy and professional burnout among Lithuanian physicians providing reanimatological and surgical treatment.

The objectives of the study:

1. Examine expression of empathy among physicians;

2. Determine expressiveness of professional burnout among physicians;

3. Examine peculiarities of correlation between empathy and professional burnout.

\section{METHODS}

On June 6, 2017, Bioethics Committee of the Lithuanian University of Health Sciences issued permission (No. BEC-SP(M)-135) to perform the study. Subjects were surveyed from October 6, 2017 till February 2, 2018. The survey was conducted in various conferences related to professions of the subjects. In the survey, 263 questionnaires were distributed, 159 filled in questionnaires were received, and the frequency of response was $60.46 \%$. In surveys of this type, response frequency greater than $60 \%$ is considered acceptable (Van der Ploeg et al., 2003). On the other hand, relatively low response frequency indicates that a little bit less than half of the subjects refused to participate in the survey. It may be assumed that for some subjects, the analysed topic was personally sensitive and it may be supposed that professional burnout experienced by them is expressed at a higher level.

Based on the provided treatment specializations, physicians were divided into two groups: reanimatological treatment (anesthesiology - reanimatology ant other, $n=81$ ) and surgical treatment (surgeons, trauma surgeons and other, $n=100$ ). Surgeons, trauma surgeons, and other medical professionals who perform invasive procedures were assigned to the group of physicians providing surgical treatment. Meanwhile anesthesiologists - reanimatologists and physicians of other specializations related to emergency conditions mostly provide urgent reanimatological treatment.

The survey covered 185 physicians, the majority of which were anesthesiologists - reanimatologists and surgeons. The sample of the survey is nonprobabilistic, convenient. Respondents by gender were distributed almost equally (see Table 1).

Table 1. Descriptive statistics of subjects by gender and specialization

\begin{tabular}{|c|c|c|c|}
\hline & & Percent & $n$ \\
\hline \multirow{3}{*}{ Gender } & Male & 40 & 74 \\
\hline & Female & 59.5 & 110 \\
\hline & Not specified & 0.5 & 1 \\
\hline \multirow{3}{*}{ Specialization } & $\begin{array}{l}\text { Reanimatological } \\
\text { treatment }\end{array}$ & 4.8 & 81 \\
\hline & Surgical treatment & 54 & 100 \\
\hline & Not specified & 2.2 & 4 \\
\hline
\end{tabular}

The age of respondents varied from young to middle age physicians, also with respect to practice experiences, there were experienced physicians as 
well as those who have recently started career (see Table 2). It is important to note that two respondents did not specify their age and three respondents did not specify their practice experiences.

The data of the present article comprise a part of a greater study. In the study, a questionnaire consisting of Jefferson Scale of Physician Empathy, Copenhagen Burnout Inventory and demographical issues (gender, age, practice experiences, and specialization) were used.

To determine empathy of physicians, Jefferson Scale of Physician Empathy (version 4.0) was used (CThomas Jefferson University, 2001; Hojat, 2016). The said scale consists of three factors:

- Perspective Taking or consideration of the patient's perspective by the physician. As maintained in studies, the said component is one of the core ingredients of cognitive empathy (Davis, 1996), which allows to develop emphatic connection between the physician and the patient (Jackson, Rainville, \& Decety, 2006);

- Compassionate care reflects the ability of physicians to understand experiences of the patient and feel his or her emotions during treatment;

- Standing in the Patient's Shoes, which indicates physician's ability to understand the patient and his or her train of thoughts.

Studies have shown that the scale is related to other empathy measuring instruments such as Interpersonal Reactivity Index (Hojat, 2016). After having determined the internal reliability of the instrument, it was obtained that the scale was appropriate for use - its Cronbach $\alpha$ was .76, minimal possible score was 20, maximal score was 140 .

To determine professional burnout of physicians, Copenhagen Burnout Inventory was used (Kristensen et al., 2005). This instrument consists of:
- Personal Burnout (6 items), which reflects the level of long-term physical and psychological fatigue that an individual experiences;

- Work-Related Burnout (7 items), which indicates the level of long-term physical and psychological fatigue that an individual perceives as related to his or her work or a consequence of work;

- Client-Related Burnout (6 items), which reflects the level of long-term physical and psychological fatigue, that an individual perceives as a consequence of relation with clients (Kristensen et al., 2005).

Thequestionnairehasnotbeenused inLithuania; therefore a double translation into Lithuanian was performed. After having determined the internal reliability of the questionnaire subscales we found that the questionnaire was appropriate for use. Cronbach $\alpha$ of Personal Burnout scale was .85, Cronbach $\alpha$ of Work-Related Burnout scale was .83 , and Cronbach $\alpha$ of Client-Related Burnout scale was .8. The minimal score of personal and patient-related burnout was 6 , maximal score was 30 , while work-related burnout minimal score was 7 and maximal score was 35 .

Values of quantitative magnitudes that satisfy the condition of normality were described by providing the average value and standard deviation. Rank magnitudes that do not meet this condition were described by providing median, inter-quarter interval, the average value, and standard deviation. Discrete values were described by providing the frequency of values and percent of relative frequency.

Distribution normality was verified using Shapiro-Wilk criterion when the sample contained 50 members and using Kolmogorov-Smirnov criterion when the sample contained more than 50 members. To determine the distribution of scores
Table 2. Descriptive age and practice experiences statistics by gender

\begin{tabular}{|l|c|c|c|c|c|}
\hline \multicolumn{2}{|c|}{} & Average & $\begin{array}{c}\text { Standard } \\
\text { deviation }\end{array}$ & Minimum & Maximum \\
\hline \multirow{3}{*}{ Age (years) } & Overall & 41.43 & 11.77 & 24 & 72 \\
\cline { 2 - 6 } & Male & 41.95 & 12.09 & 24 & 63 \\
\cline { 2 - 6 } & Female & 41.1 & 11.59 & 24 & 72 \\
\hline \multirow{2}{*}{$\begin{array}{l}\text { Practice } \\
\text { experiences } \\
\text { (years) }\end{array}$} & Overall & 15.93 & 12.13 & 0.17 & 43 \\
\cline { 2 - 6 } & Male & 16.43 & 12.07 & 0.17 & 38 \\
\cline { 2 - 6 } & Female & 15.59 & 12.21 & 0.17 & 43 \\
\hline
\end{tabular}


of two independent samples, Student- $T$ test was used when samples met the normality criterion and Mann-Whitney test when samples did not meet the said criterion. The determined level of significance was $p \leq .05$.

To determine correlation among psychological constructs by specialization, age and practice experiences of physicians, the said indicators were divided into three groups based on subject distribution in the sample. By age, physicians were divided into younger (up to 32 years, $n=$ 53), middle aged (from 33 to 44 years, $n=55$ ), and senior (from 45 years on, $n=75$ ). By practice experiences, physicians were divided into having little experience (up to 6 years, $n=60$ ), with average experience (from 7 to 20 years, $n=52$ ), and experienced (from 21 years on, $n=70$ ).

The study data were processed using IBM SPSS Statistics and Microsoft Excel 2010 software.

\section{RESULTS}

Empathy expression among physicians. To determine empathy expression among physicians, empathy scale score distribution was assessed. It was determined that empathy scale score distribution did not meet the normality criterion (see Table 3). Comparison of empathy average of Lithuanian physicians with the average of empathy of physicians in those countries where empathy scores were measured using Jefferson Scale of Physician Empathy shows that the score of Lithuanian medical professionals was lower than that of Polish (113; $S E=1.33)$, American (120; $S E=0.45)$ (Shariat, Eshtad, \& Ansari, 2010), Italian $(115.1 ; S E=0.91)($ Di Lillo, Cicchetti, Lo Scalzo, Taroni, \& Hojat, 2009), Japanese (104.3; $S E=0.65)$ (Kataoka, Koide, Ochi, Hojat, \& Gonnella, 2009), and Iranian (110; $S E=0.94$ ) (Shariat et al., 2010) physicians. It was also determined that the said difference was statistically significant $(p<.001)$.

When determining empathy expression among physicians, subjects were divided into less emphatic and more emphatic physicians based on the sample median. It may be observed that subjects between these samples were distributed evenly (see Table 4). When assessing physician empathy differences by gender, age, practice experiences, and specialization, significant differences were not determined $(p>.05)$.

Peculiarities of the experienced professional burnout. To determine the expression of professional burnout among practicing physicians, score distribution in each subscale was determined. Considering that subscale scores are continuous values, their distribution was determined by the criterion of normality. It was determined that the subscale of patient-related burnout met the criterion of normality (see Table 5).

\begin{tabular}{|l|c|c|c|c|c|c|}
\hline & $\boldsymbol{p}$ value & Average & $\begin{array}{c}\text { Standard } \\
\text { deviation }\end{array}$ & Median & $\begin{array}{c}\text { Inter-quarter } \\
\text { interval }\end{array}$ & Standard error \\
\hline Empathy & .03 & 95.57 & 13.81 & 95.34 & $85-106$ & 1.02 \\
\hline
\end{tabular}

Table 3. Descriptive statistics of Jefferson Scale of Physician Empathy

\begin{tabular}{|c|c|c|}
\hline & & n (per cent) \\
\hline \multirow{3}{*}{ Empathy } & Less emphatic $(<95.34)$ & $91(49.2)$ \\
\hline & More emphatic (> 95.35) & $91(49.2)$ \\
\hline & Did not respond & $3(1.6)$ \\
\hline
\end{tabular}

Table 4. Distribution of expression of Jefferson Scale of Physician Empathy among subjects

\begin{tabular}{|l|c|c|c|c|c|c|}
\hline & $p$ value & Average & $\begin{array}{c}\text { Standard } \\
\text { deviation }\end{array}$ & Median & $\begin{array}{c}\text { Inter-quarter } \\
\text { interval }\end{array}$ & $\begin{array}{c}\text { Standard } \\
\text { error }\end{array}$ \\
\hline Personal burnout & .036 & 2.84 & 0.66 & 2.83 & $2.33-3.33$ & 0.05 \\
\hline $\begin{array}{l}\text { Work-related } \\
\text { burnout }\end{array}$ & $<.001$ & 2.52 & 0.68 & 2.43 & $2-3$ & 0.05 \\
\hline $\begin{array}{l}\text { Patient-related } \\
\text { burnout }\end{array}$ & .1 & 2.55 & 0.73 & 2.5 & $2-3.13$ & 0.05 \\
\hline
\end{tabular}

Table 5. Descriptive statistics of question+naire scales of Copenhagen Burnout Inventory 
Taking into account subscale medians, the sample of subjects was divided into physicians who experienced less of professional burnout and those who experienced more of professional burnout. It was obtained that the majority of subjects experienced more expressed level of personal burnout (see Table 6).

When determining correlation of professional burnout with demographic parameters of physicians it was obtained that younger physicians experienced statistically significantly greater workrelated burnout than older physicians (see Table 7).
Statistically significant differences by gender, practice experiences, and specialization were not determined $(p>.05)$.

Empathy correlation with professional burnout. To determine professional burnout correlation with empathy of physicians considering that not all distributions were distributed by the normal distribution, Spearman correlation coefficient was applied. It was obtained that components of professional burnout were not associated with the empathy of physicians (see Table 8).
Table 6. Distribution of Copenhagen Burnout Inventory Subscale expression among subjects

\begin{tabular}{|l|l|c|}
\hline \multirow{4}{*}{ Personal burnout } & Expression of professional burnout & $\boldsymbol{n}$ (per cent) \\
\hline \multirow{4}{*}{ Work-related burnout } & Experience less $(<2.83)$ & $64(34.6)$ \\
\cline { 2 - 3 } & Experience more $(>2.84)$ & $116(62.7)$ \\
\cline { 2 - 3 } & Did not respond & $5(2.7)$ \\
\hline \multirow{3}{*}{ Patient-related burnout } & Experience less $(<2.43)$ & $99(53.5)$ \\
\cline { 2 - 3 } & Experience more $(>2.44)$ & $81(43.8)$ \\
\cline { 2 - 3 } & Did not respond & $5(2.7)$ \\
\cline { 2 - 3 } & Experience less $(<2.5)$ & $91(49.2)$ \\
\cline { 2 - 3 } & Experience more $(>2.51)$ & $89(48.1)$ \\
\cline { 2 - 3 } & Did not respond & $5(2.7)$ \\
\hline
\end{tabular}

Table 7. Statistical and practical impact Values of Copenhagen Burnout Inventory Subscales by age

\begin{tabular}{|c|c|c|c|}
\hline & & p value & Mean ranks \\
\hline \multirow{3}{*}{ Personal burnout } & Younger & \multirow{3}{*}{.19} & 90.75 \\
\hline & Middle aged & & 98.46 \\
\hline & Older & & 81.75 \\
\hline \multirow{3}{*}{ Work-related burnout } & Younger & \multirow{3}{*}{.04} & 99.5 \\
\hline & Middle aged & & 95.12 \\
\hline & Older & & 77.76 \\
\hline \multirow{3}{*}{ Patient-related burnout } & Younger & \multirow{3}{*}{.48} & 95.68 \\
\hline & Middle aged & & 90.04 \\
\hline & Older & & 84.48 \\
\hline
\end{tabular}

Table 8. Correlation matrix of Empathy and Professional Burnout

Note. ${ }^{*} p \leq .05, * * p \leq .001$. Spearman nonparametric correlation coefficient was applied.

\begin{tabular}{|l|c|c|c|c|}
\hline & Empathy & Personal burnout & $\begin{array}{c}\text { Work-related } \\
\text { burnout }\end{array}$ & $\begin{array}{c}\text { Patient- related } \\
\text { burnout }\end{array}$ \\
\hline $\begin{array}{l}\text { SCALE/ } \\
\text { SUBSCALE }\end{array}$ & \multicolumn{3}{|c|}{ Copenhagen Burnout Inventory Scale } \\
\hline Empathy & 1 & & & \\
\hline $\begin{array}{l}\text { Personal } \\
\text { burnout }\end{array}$ & -.02 & 1 & 1 & \\
\hline $\begin{array}{l}\text { Work-related } \\
\text { burnout }\end{array}$ & -.08 & $.76 * *$ & & \\
\hline $\begin{array}{l}\text { Patient-related } \\
\text { burnout }\end{array}$ & -.14 & $.63 * *$ & $.79 * *$ & 1 \\
\hline
\end{tabular}




\section{DISCUSSION}

The study has revealed that empathy of physicians, their personal and patient-related burnout do not correlate with such demographic indicators as gender, age, practice experiences, and specialization. On the other hand, it has been obtained that younger physicians experience more work-related burnout, but expression of this professional burnout component did not differ statistically significantly by gender, practice experiences, and specialization. It has been determined that professional burnout is not associated with empathy.

It has been determined that expression of empathy of Lithuanian physicians was statistically significantly lower than that of medical professionals of other countries. Empathy scores presented in articles vary from 104.3 $(S E=0.65$; Japan) (Kataoka et al., 2009) to $120(S E=0.45$; U.S.A.) (Shariat et al., 2010). It has been observed that empathy scores in eastern countries are lower as compared with the western countries. However, significant differences among countries may be explained not just by cultural differences and, therefore, different traditions of medicine. It may be observed that in some countries empathy of physicians is being paid less attention. In Japan and Iran, the work of physicians is oriented towards science, and they rarely maintain contact with patients (Shariat et al., 2010). Such regularities allow assuming that Lithuanian physicians do not have sufficient knowledge about the importance of empathy or they are not inclined to maintain connection with patients, which may be related both to medical training programs and health care situation in the country. However, it should not be ignored that only physicians who provide reanimatological and surgical care were surveyed while in studies it is noted that physicians of the said specialization tend to have the lowest empathy (Hojat et al., 2002 a).

Empathy correlation with gender has not been completely determined in scientific studies - some studies maintain that females are more emphatic than males (Hojat et al., 2001; Hojat et al., 2002 a; Shariat et al., 2010). Results of the present study contradict to the above mentioned data - it was determined that empathy was not associated with gender. As to the empathy correlation with age and practice experiences, scientific articles observe that practice experiences are determined as a factor that has impact on empathy despite the age of a physician. Physicians with greater practice experiences are more emphatic than those who have less experience (Shariat et al., 2010). Results of the present study in part contradict to the literature data - it was determined that empathy did not correlate with age or practice experiences. It may be assumed that the ability to emphatically respond to the patient is not developed while working and maybe this communication aspect should be developed during medical studies.

Meanwhile, in the scientific literature it is observed that there is a lack of studies analysing correlation between empathy and medical profession. On the other hand, the current studies establish correlation between empathy of physicians and specialization - those who have chosen people oriented specializations, such as general practitioners, pediatricians or psychiatrists are more emphatic than physicians who have chosen technology oriented specializations, such as anesthesiologists, surgeons or radiologists (Hojat et al., 2001; Hojat et al., 2002 a). In the present study, no correlation between empathy and specialization has been determined. On the other hand, it is significant to note that only physicians providing reanimatological and surgical treatment were surveyed. Both specializations, as specified in the scientific literature, are technology oriented, and these doctors have less frequent contact with patients (Hojat et al., 2001). Also, both specializations are similar in the nature of work; therefore correlation with specialization could not be determined.

As to the professional burnout correlation with demographical characteristics, no unanimous conclusion could be found in the literature. Some studies maintain that females experience more professional burnout than males (Maslach et al., 2001), whereas other studies determine that gender does not correlate with work-related burnout (Gasiūnienè, 2013; Ozkula \& Durukan, 2017). Results of the present study supplement the latter scientific literature - both female and male physicians experience the same professional burnout. In articles, the said tendency is attempted to be explained based on the effects of world healthcare policy changes in recent years (Ozkula \& Durukan, 2017). It may also be assumed that the said tendency is related to the workload - in 
medicine, both females and males are exposed to the same workload, therefore they experience the same expression of professional burnout independent of their gender.

Meanwhile in the scientific literature a clear tendency is established that practice experiences and age correlate with professional burnout - workrelated burnout syndrome is more clearly expressed among younger and less experienced employees (Maslach et al., 2001; Ozkula \& Durukan, 2017; Potter, 2006). The data of the present study supplement the insights of scientific literature. It has been established that younger physicians experience more work-related burnout. On the other hand, none of the professional burnout components was associated with practice experiences. In the scientific literature, the tendency of professional burnout association with practicing experiences is interpreted cautiously taking into account the fact that employees who experience more work-related burnout are inclined to leave the job or to requalify, therefore individuals who from the beginning experienced less work-related burnout syndrome stay on the job (Maslach et al., 2001). On the other hand, the fact that younger physicians experience more work-related burnout than older ones may be explained by the lack of professional experience quite often young physicians are new on the job, they have not encountered more complicated situations, therefore they experience more stress and anxiety about the quality of their work, which all combined may stipulate more expressed workrelated burnout.

In the studies it has been established that empathy and professional burnout are negatively correlated - physic with high empathy experience less professional burnout (Yuguero, Marsal, Esquerda, \& Soler-Gonzalez, 2017). On the other hand, in other studies it is emphasized that the necessity of being empathic stimulates professional burnout (Maslach et al., 2001). Results of the present study contradict to the literature data. It has been established that professional burnout is not associated with empathy. Therefore, it may be assumed that professional burnout is more associated with the character of work than with such personality factors of physicians as empathy.

The present study, like many others, has some limitations. Among the said limitations are time and cultural differences that limit the possibility to compare the obtained results in the study with the data of foreign researchers. On the other hand, such studies in Lithuania are not numerous, moreover, we could not find studies that would explore professional burnout association with empathy of physicians, and therefore the obtained results significantly supplement the available data. The other possible limitation of the present study is the fact that multi-dimensional analysis was not performed.

Equal distribution of both genders in the study may be viewed as an advantage. Considering relatively equal distribution of females and males in the study, it may be maintained that the obtained data reflect tendencies in both genders. Also, as an advantage, it is important to mention that the present study allows clearer understanding of the job specificity of physicians, emotional experiences that arise at work and consequences of the said experiences. It would be expedient to analyse the current differences of empathy of physicians in further studies and to determine factors that cause the said differences. Studies on this subject would contribute to the improvement of emotional and psychological state of physicians and would ensure rendering medical services of higher quality.

\section{CONCLUSIONS}

1. Sizes of groups of less expressed and more expressed empathy were similar. The empathy of Lithuanian physicians was less expressed than that of medical professionals from other countries. Empathy of physicians who provide reanimatological and surgical treatment was not associated with such demographic indicators as gender, age, practice experiences, and specialization;

2. Among physicians who provide reanimatological and surgical treatment, personal burnout was more clearly expressed, whereas group sizes of physicians experiencing greater and lesser work-related and patient-related burnout were similar. Younger physicians experienced more work-related burnout than older physicians. Correlation of this construct with other demographic parameters was not determined. Personal and patient-related burnout were not associated with demographic characteristics of physicians;

3. Empathy was not associated with professional burnout of physicians who provide reanimatological and surgical treatment.

Conflict of interests. The research was not funded by any organization or company. 


\section{REFERENCES}

Ahrweiler, F., Neumann, M., Goldblatt, H., Hahn, E. G., \& Scheffer, Ch. (2014). Determinants of physician empathy during medical education: Hypothetical conclusions from an exploratory qualitative survey of practicing physicians. BMC Medical Education, 14. https://doi.org/10.1186/1472-6920-14-122

Davis, M. H. (1994). Empathy: A social psychological approach. Boulder, CO: Westview.

Di Lillo, M., Cicchetti, A., Lo Scalzo, A., Taroni, F., \& Hojat, M. (2009). The Jefferson Scale of Physician Empathy: Preliminary psychometrics and group comparisons in Italian physicians. Academic Medicine, 84(9), 1198-1202. doi: 10.1097/ACM.0b013e3181b17b3f Freudenberger, H. J. (1974). Staff burn-out. Journal of Social Issues, 30, 159-165.

Gasiūniene, L. (2013). Profesinio perdegimo paplitimas tarp Lietuvos akušeriu ginekologų: magistro baigiamasis darbas. Kaunas: Lietuvos sveikatos mokslų universitetas. Hojat, M., Gonnella, J. S., Mangione, S., Nasca, T. J., Veloski, J. J., Erdmann, J. B., ... Magee, M. (2002B). Empathy in medical students as related to academic performance, clinical competence and gender. Medical Education, 36, 522-527.

Hojat, M., Gonnella, J. S., Nasca, T. J., Mangione, S., Vergare, M., \& Magee, M. (2002a). Physician empathy: Definition, components, measurement, and relationship to gender and specialty. American Journal of Psychiatry, 159(9), 1569-1563. https://doi.org/10.1176/appi. ajp.159.9.1563

Hojat, M. (2016). Jefferson Scale of Empathy (JSE): User guide. USA: Thomas Jefferson University.

Hojat, M., Mangione, S., Nasca, T. J., Cohen, M. J. M., Gonnella, J. S., Erdmann, J. B., \& Magee, M. (2001). The Jefferson Scale of Physician Empathy: Development and preliminary psychometric data. Educational and Psychological Measurement, 61, 349-365.

Jackson, P., L., Rainville, P., \& Decety, J. (2006). To what extent do we share the pain of others? Insight from the neural bases of pain empathy. Pain, 125, 5-9. https:// doi.org/10.1016/j.pain.2006.09.013

Kataoka, H. U., Koide, N., Ochi, K., Hojat, M., \& Gonnella, J. S. (2009). Measurement of empathy among Japanese medical students: Psychometrics and score differences by gender and level of medical education. Academic Medicine, 84(9), 1192-1197. doi: 10.1097/ ACM.0b013e3181b180d4

Kristensen, T. S., Borritz, M., Villadsen, E., \& Christensen, K. B. (2005). The Copenhagen Burnout Inventory: A new tool for the assessment of burnout. Work and Stress, 19(3), 192-207. https://doi. org/10.1080/02678370500297720

Lathrop, D. (2017). Disenfranchised Grief and Physician Burnout. Annals of Family Medicine, 15(4), 375-378. doi: 10.1370/afm.2074

Maslach, C., Schaufeli, W. B., \& Leiter, M. P. (2001). Job burnout. Annual Review of Psychology, 52, 397422. https://doi.org/10.1146/annurev.psych.52.1.397
Maslach, Ch., \& Leiter, M. P. (2016). Understanding the burnout experience: Recent research and its implications for psychiatry. World Psychiatry, 15, 103-111. doi: 10.1002/wps.20311

Ozkula, G., \& Durukan, E. (2017). Burnout syndrome among physicians: The role of socio-demographic characteristics. The Journal of Psychiatry and Neurological Sciences, 30, 136-144. doi: 10.5350/DAJPN2017300207 Pedersen, R. (2009). Empirical research on empathy in medicine - A critical review. Patient Education and Counseling, 76, 307-322. doi: 10.1016/j.pec.2009.06.012

Potter, C. (2006). To what extent do nurses and physicians working within the emergency department experience burnout: A review of the literature. Australasian Emergency Nursing Journal, 9, 57-64. doi: 10.1016/j. aenj.2006.03.006

Regehr, C., Goldberg, G., \& Hughes, J. (2002). Exposure to human tragedy, empathy, and trauma in ambulance paramedics. American Journal of Orthopsychiatry, 72(4), 505-513. doi: 10.1037/0002-9432.72.4.505

Scheepers, R. A., Boerebach, B. C., M., Arah, O. A., Heineman, M. J., \& Lombarts, K. (2015). A systematic review of the impact of physicians' occupational wellbeing on the quality of patient care. International Journal of Behavioral Medicine, 22, 683-698. doi: 10.1007/s12529-015-9473-3

Shariat, S., V., Eshtad, E., \& Ansari, S. (2010). Empathy and its correlates in Iranian physicians: A preliminary psychometric study of the Jefferson Scale of Physician Empathy. Medical Teacher, 32, 417-421. https://doi.org /10.3109/0142159X.2010.498488

Steinhausen, S., Ommen, O., Antoine, S., Koehler, T., Pfaff, H., \& Neugebauer, E. (2014). Short- and long-term subjective medical treatment outcome of trauma surgery patients: the importance of physician empathy. Patient Preference and Adherence, 8, 1239-1253. https://doi. org/10.1016/j.pec.2013.12.007

Van der Ploeg, E., Kleber, S. M., \& Dorresteijn, R. J. (2003). Critical incidents and chronic stressors at work: Their impact on forensic doctors. Journal of Occupational Health Psychology, 8(2), 157-166.

Venytė, R. (2008). Emociniu sunkumu priežastys ir ju kontrolès galimybès terminalinès būklès pacientus prižiūrinčiu slaugytojų darbe (Magistro baigiamasis darbas). Kaunas: Lietuvos sveikatos mokslų universitetas.

Yuguero, O., Marsal, J. R., Esquerda, M., \& SolerGonzalez, J. (2017). Occupational burnout and empathy influence blood pressure control in primary care physicians. BMC Family Practice, 18(63). https://doi. org/10.1186/s12875-017-0634-0

Zdanavičienè, D. (2013). Greitosios medicinos pagalbos darbuotoju darbo organizavimo ypatumu ìvertinimas: magistro baigiamasis darbas. Kaunas: Lietuvos sveikatos mokslų universitetas. 